\title{
Electrostatic Effects in Biosorption. The Role of the Electrochemistry
}

\author{
Pablo Lodeiro, José L. Barriada, Roberto Herrero, \\ Manuel E. Sastre de Vicente* \\ Departamento de Química Física e Enxeñería Química I, University of A Coruña, \\ Alejandro de la Sota 1, 15008 A Coruña, Spain
}

\begin{abstract}
Biosorption is the passive sequestration of pollutants by non-metabolizing non-living biomass. The technique emerged in 1980's as a possible alternative method for wastewater treatments in an environmentally friendly manner. In this paper it is shown that a basic research in biosorption processes is closely related to the field of Electrochemistry according to the conceptual division of this area in Ionics and Electrodics.
\end{abstract}

Keywords: electrochemistry, biosorption, master curve, electrostatics effects.

\section{Introduction}

In order to alleviate heavy metal burden of wastewaters before discharging into waterways, a number of physicochemical methods, such as chemical precipitation, adsorption, solvent extraction, ion exchange, membrane separation, electrolysis, etc., have commonly been employed. However, these methods have several disadvantages such as incomplete metal removal, expensive equipment, high reagent or energy requirements and generation of toxic sludge or other waste products that require disposal. Further, they may be ineffective or extremely expensive when metal concentration in wastewater is in the range 1$100 \mathrm{mg} / \mathrm{L}$.

Biosorption is a relatively new technique that emerged in the 1980's and gained a considerable amount of attention since it has shown to be very promising in the removal of contaminants from effluents in an environmentally friendly manner $[1]$.

\footnotetext{
* Corresponding author. E-mail address: eman@udc.es
} 


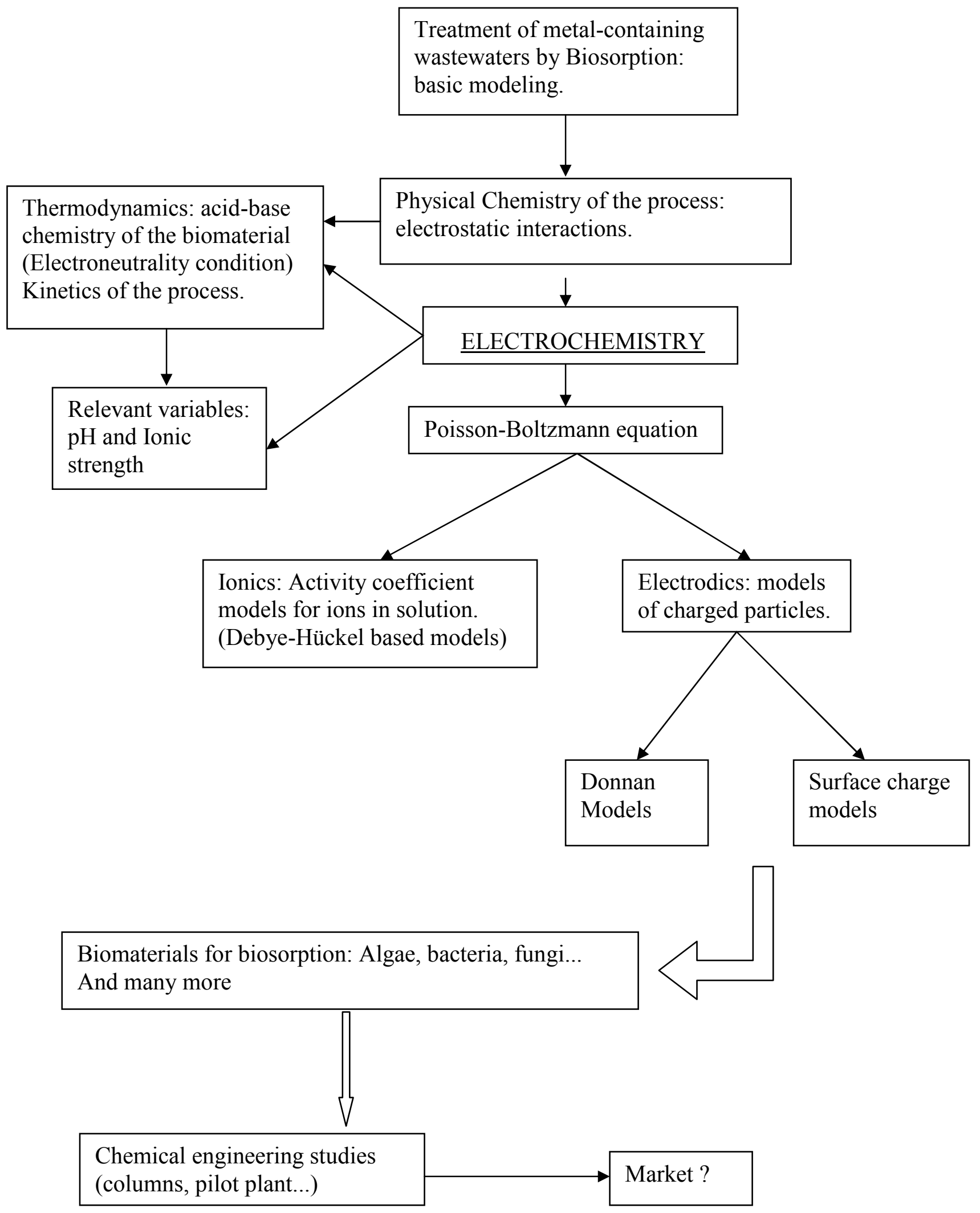

Figure 1. Involvement of electrochemistry in biosorption modelling. 
Table 1. Some activity coefficient models proposed in literature.

\begin{tabular}{|c|c|}
\hline Model & Function \\
\hline Brönsted & $\log \gamma_{ \pm}=-3 \alpha \sqrt{c}-2 \beta \cdot c$ \\
\hline $\begin{array}{l}\text { Limiting } \\
\text { Debve-Hückel }\end{array}$ & $\log \gamma_{ \pm}=-A\left|z_{+} z_{-}\right| \sqrt{I}$ \\
\hline Extended & $-A\left|z_{+} z_{-}\right| \sqrt{I}$ \\
\hline Debye-Hückel & $\log \gamma_{ \pm}=\frac{11+\operatorname{Ba} \sqrt{I}}{1+B}$ \\
\hline Hückel & $\log \gamma_{ \pm}=\frac{-A\left|z_{+} z_{-}\right| \sqrt{I}}{1+B a \sqrt{I}}+\beta c$ \\
\hline Guggenheim & $\ln \gamma_{M X}=-\frac{A^{\prime}\left|z_{M} z_{X}\right| \sqrt{I}}{1+\sqrt{I}}+\frac{2 v_{M}}{v_{M}+v_{X}} \sum_{a} \beta_{M a} m_{a}+\frac{2 v_{X}}{v_{M}+v_{X}} \sum_{c} \beta_{c X} m_{c}$ \\
\hline Pitzer & $\begin{aligned} \ln \gamma_{M^{+}} & =z_{M}^{2} f^{\gamma}+2 \sum_{a} m_{a}\left[B_{M a}+(\Sigma m z) C_{M a}\right]+2 \sum_{c} m_{c} \theta_{M c}+ \\
& +\sum_{c} \sum_{a} m_{c} m_{a}\left(z_{M}^{2} B_{c a}^{\prime}+z_{M} C_{c a}+\psi_{M c a}\right)+\frac{1}{2} \sum_{a} \sum_{a^{\prime}} m_{a} m_{a^{\prime}}\left(z_{M}^{2} \theta_{a a^{\prime}}^{\prime}+\psi_{M a a^{\prime}}\right)+ \\
& +\frac{z_{M}^{2}}{2} \sum_{c} \sum_{c^{\prime}} m_{c} m_{c^{\prime}} \theta_{c c^{\prime}}^{\prime}\end{aligned}$ \\
\hline MSA & $\begin{aligned} \log \gamma_{i} & =-\frac{\alpha^{2} z_{i}^{2}}{4 \pi} \frac{\Gamma}{1+\Gamma \sigma_{i}}-\frac{\alpha^{2} z_{i} \sigma_{i}}{4\left(1+\Gamma \sigma_{i}\right)} \frac{P_{n}}{\Delta}+\frac{\pi \alpha^{2} \sigma_{i}^{3}}{16}\left(\frac{1}{1+\Gamma \sigma_{i}}-\frac{1}{3}\right) \frac{P_{n}^{2}}{\Delta^{2}}- \\
& -\ln \Delta+\frac{\sigma_{i}^{3} X_{0}+3 \sigma_{i}^{2} X_{1}+3 \sigma_{i} X_{2}}{\Delta}+\frac{3 \sigma_{i}^{3} X_{1} X_{2}+9 / 2 \sigma_{i}^{2} X_{2}^{2}}{\Delta^{2}}+\frac{3 \sigma_{i}^{3} X_{2}^{3}}{\Delta^{3}}\end{aligned}$ \\
\hline Sammartano & $\log \gamma_{z}=\frac{-A z^{2} \sqrt{I}}{1+B \sqrt{I}}+C_{z} I+D_{z} I^{3 / 2}$ \\
\hline
\end{tabular}

Comments

Applicable at moderate

concentration

Applicable at very

diluted concentration

Applicable at diluted

concentration

Applicable at moderate

concentration

Applicable at moderate

concentration

Applicable at very

high concentration

Inclusion of size and

charge effects

Empirical modification

of the Extended

Debye-Hückel limiting

law
$[40,41,6]$

Reference

$[34,35]$

$[36,37]$

$[36,37]$

*For symbol meaning and interpretation see references mentioned in the table and references therein. 
Biosorption, as it has been defined, perceived and investigated is an adsorption process based on the passive sequestration by non-metabolizing, non-living biomass [2]. Conceptually, biosorption is distinguished from bioaccumulation, which is active metabolically mediated transport and deposition of chemical species. Biosorbents are generally inexpensive because they are either naturally abundant or found as waste material from certain processes.

Biomass particles contain different chemically active groups, which are partially ionised in aqueous solution. The resulting interactions of these ionised groups with their surroundings can be rationalised from a wide perspective in the framework of electrochemistry.

In fact, based on the conceptual classification done by Bockris [3], who divides electrochemistry in: Ionics, which is concerned with the physical chemistry of ionic solutions, and Electrodics, to the electrically charged interfaces, it can be shown that basic studies leading to fundamental information about the biosorption process are well supported on ingredients supplied by Ionics (speciation and activity coefficient models in solution) and Electrodics (models for charged particles in an electrolytic medium), as Fig. 1 shows.

\section{Ionic electrochemistry: speciation and activity coefficients}

Biosorption depends on speciation in solution. The case of biosorption of heavy metals is a good example. In addition to temperature and solvent, a factor influencing speciation, through its effect on the equilibrium constant, is the activity of species in solution according to equation:

$$
K^{T}=K^{*} \cdot Q(\gamma)
$$

where the thermodynamic constant, $K^{\mathrm{T}}$, for each equilibrium, can be expressed as the product of stoichiometric constant, $K^{*}$, times the activity coefficient quotient $Q(\gamma)$. The expression for $\log (\gamma)$ and $\log (Q(\gamma))$ is dictated by the different theoretical approaches, associated to the theory of electrolytes, (Table 1). Most treatments rely on the Debye-Hückel limiting law, although their final purpose is their possible application to moderate or high ionic strengths. The ionic strength, I, even eighty five years after its introduction in Chemistry, is an important variable in the description of this kind of models [4, 5].

The different theories and models for specific ionic interactions assume electrolytes to be fully dissociated into ions and express their interactions in terms of coefficients that are generally functions of the ionic strength and various specific parameters for the system concerned. Also different approaches, normally based in the Specific Interaction Theory (SIT) of Brönsted-Guggenheim, being the more complete development the Pitzer's equations [6], have been used by different workers either in simple electrolytes or in mixtures such as synthetic seawater for different kinds of ligands [7, 8, 9, 10]. Other alternatives based on more recent theoretical developments such as the Mean Spherical Approximation (MSA), which is an integral-equation based theory, use charge, size, concentration and temperature as direct parameters in the expression for activity coefficients and the subsequent calculation of the term $\log (\mathrm{Q}(\gamma))$. For instance, this approach allows 
studying effects of size on the chemical equilibria involved, not easily accessible in SIT expressions [11].

\section{Electrodics: modeling charged particles}

Generally, a biomaterial with sorbent properties contains natural biopolymers. It also has a relatively high number of complexing sites, and exhibits the following characteristics: polyfunctionality (the binding sites can be chemically heterogeneous), conformational changes (the steric conformation of the complexants can vary with the chemical conditions of the medium, such as $\mathrm{pH}$, ionic strength or amount of bound cation), and polyelectrolytic effect (many of the biomaterials complexing sites carry a high local charge concentration, which influences the stability of the complexes).

Taking into account that in most cases a negative charge associated to the dissociation of acidic groups of biomaterials is developed, the interactions of these complex systems with their environment, specially with metals, are going to be necessarily dependent both on the acid-base properties of the biomaterial and on the metal speciation in solution; so variables such as $\mathrm{pH}$, ionic strength or metal/site ratio are very relevant and they will determine the relative importance of the observed effects, mainly those associated to electrostatic interactions.

If the biosorption of protons is considered, the value of a $\mathrm{p} K$ for the acid-base reaction (Equation 2) associated to a site is a function of $\mathrm{pH}$, in contrast to what happens with simple ligands:

$$
A H^{(Q-1)-} \leftrightarrows A^{Q-}+H^{+}
$$

In monofunctional polymers, for example, the deviations from ideality are usually ascribed to electrostatic effects (apart from conformational effects). Therefore, two contributions to the overall standard free energy change of the dissociation process can be considered:

$$
\Delta G_{\text {diss }}=\Delta G_{\text {int }}+\Delta G_{\text {elec }}
$$

where $\Delta G_{\text {int }}$ represents the chemical free energy due to the reaction of the functional group itself and $\Delta G_{\text {elec }}$ represents the coulombic free energy due to the electrostatic interactions between the proton and the charges of the polyanion. In terms of equilibrium constants it can be written:

$$
K=K_{\text {int }} \cdot K_{\text {elec }}
$$

and a clear analogy with Equation 1 for reactions with simple monodisperse ligands can be drawn.

Following the extensive work carried out by different researchers in the area of humic and fulvic acids (see Turner [12] and Tipping [13] for reviews) it can be stated that all electrostatic models for biosorbents will be based on Equation 4, 
with different approaches to calculate $\mathrm{K}_{\text {elec }}$ and diverse methods to express the possible distribution of active groups (sites) in the biosorbent.

The conditional equilibrium constant corresponding to the dissociation represented in Equation 2 is:

$$
K=\frac{\left[A^{Q-}\right]\left[H^{+}\right]_{0}}{\left[A H^{(Q-1)-}\right]}
$$

On the other hand the concentration of protons near the particle, $\left[\mathrm{H}^{+}\right]$, can be related with its concentration (or activity) in solution, $\left[\mathrm{H}^{+}\right]_{0}$, an experimentally accessible quantity, through a Boltzmann factor:

$$
\left[H^{+}\right]=\left[H^{+}\right]_{0} \exp \left(-\frac{F \psi}{R T}\right)
$$

where $\Psi$ is the characteristic smeared-out electrostatic potential in the solution at the location of the binding sites of the biosorbent.

In case the proton activity is considered, a correction for the activity coefficient in solution for the proton will be required and depending on experimental conditions, a model from Table 1 will be chosen.

The value of $\Psi$ is often estimated by solving the Poisson-Boltzmann equation $[14,15,16]$, which implies the description of the solid-liquid interface with a suitable model. By analogy with models initially developed for humic and fulvic acids [17], two groups of electrostatic models can essentially be categorised differing in the structure of the biosorbent particles (Fig. 2). A first group considers ion-impermeable particles, in which the charge is placed on the surface. These models are based implicitly or explicitly on the double layer theory and are typical, for example, of oxide surfaces. These models have been employed for cadmium biosorption on bacterial surfaces [18, 19, 20], and proton binding [21]. The second group considers ion-permeable particles, which can be viewed as a gel into which ions can penetrate, or Donnan models, which have been mainly used for interpreting biosorption data on marine algae [22, 23, 24, $25,26,27,28]$. Application of these two models in biosorption systems is reflected in Table 2. Comparisons between different models including descriptions directly based in specific-ion interaction theory, so in Equation 1, have also been carried out for alginic acid [21, 23, 29], the main acid component in brown seaweed. 
- Negative groups

Counter ions

+ Potential decay

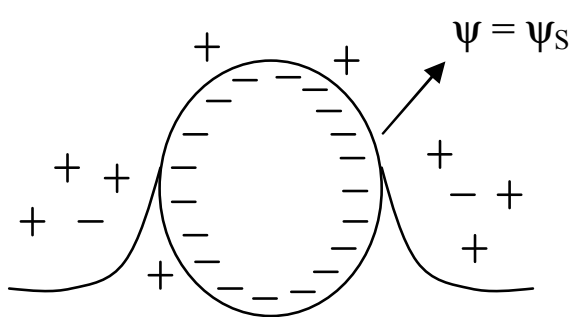

(a)

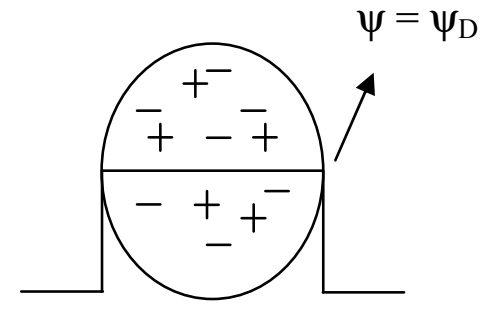

(b)

Figure 2. Schematic representation of the impermeable sphere (a) and Donnan (b) models. Adapted from the article of Avena et al. [46].

\section{Testing electrostatic models: the electroneutrality condition and the master curve approach}

The electroneutrality condition for solutions, although is not a fundamental law of nature, is an excellent approximation to reality on the basis of the Poisson's equation of electrostatics [30]. The master curve approach is built on that condition. The method entails to carry out potentiometric titrations of biosorbent suspensions against a simple ion, commomly the proton, in order to test an acceptable model for the charged particles. The experimental proton titration data can be transformed through the electroneutrality condition into data of net charge $(\mathrm{Q})$, proton coverage $(\theta)$, dissociation degree, etc., of the biosorbent versus $\mathrm{pH}_{0}$ :

$$
Q=\frac{1}{C_{\text {biosorbent }}}\left(\left[H^{+}\right]_{0}+\frac{V_{b} C_{b}-V_{a} C_{a}}{V_{0}+V_{b}+V_{a}}-\frac{K_{w}}{\left[H^{+}\right]_{0}}\right)
$$

In Equation 7, Q is the charge expressed as moles of protons dissociated per kilogram of biomass, $V_{0}$ is the initial volume of solution in the titration cell, $\mathrm{C}_{\text {biosorbent }}$ is the concentration of biomass in the cell, in kilograms of dry weight per liter, $V_{\mathrm{a}}, V_{\mathrm{b}}, C_{\mathrm{a}}$ and $C_{\mathrm{b}}$ are the volume and the concentration of added acid and base, respectively, and $K_{\mathrm{w}}$ is the ionic product of water. 
Table 2. Application of solid-liquid interface models in biosorption processes

\begin{tabular}{|c|c|c|}
\hline Biosorption system & $\begin{array}{c}\text { Model of charged particle } \\
\text { of biosorbent }\end{array}$ & References \\
\hline $\begin{array}{l}\text { Binding of heavy metals to } \\
\text { algal surfaces }\end{array}$ & Surface model & {$[43]$} \\
\hline $\begin{array}{l}\text { Cd adsorption onto } \\
\text { bacterial surfaces }\end{array}$ & Surface model & {$[20]$} \\
\hline $\begin{array}{l}\text { Metal adsorption onto a } \\
\text { natural polysaccharide } \\
\text { (sugar beet pulp) }\end{array}$ & Surface model & {$[18]$} \\
\hline $\begin{array}{l}\text { Heavy metal sorption onto } \\
\text { aminated chitosan }\end{array}$ & Surface model & {$[44]$} \\
\hline $\begin{array}{l}\text { Adsorption of metals onto } \\
\text { Gram negative bacteria }\end{array}$ & Surface model & [19] \\
\hline $\begin{array}{l}\text { Biosorption of protons onto } \\
\text { algae Sargassum }\end{array}$ & Donnan model & {$[27]$} \\
\hline $\begin{array}{l}\text { Biosorption of divalent } \\
\text { metals onto Sargassum sp. }\end{array}$ & Donnan model & {$[28]$} \\
\hline $\begin{array}{l}\text { Biosorption of heavy } \\
\text { metals onto Sargassum sp. }\end{array}$ & Donnan model & {$[25]$} \\
\hline $\begin{array}{l}\text { Biosorption of metals onto } \\
\text { several marine seaweeds }\end{array}$ & Donnan model & {$[26]$} \\
\hline $\begin{array}{l}\text { Biosorption of protons onto } \\
\text { several brown seaweeds }\end{array}$ & Donnan model & {$[22]$} \\
\hline $\begin{array}{l}\text { Biosorption of copper on } \\
\text { calcium alginate }\end{array}$ & Donnan model & {$[45]$} \\
\hline $\begin{array}{l}\text { Biosorption of protons onto } \\
\text { seaweed biomass }\end{array}$ & $\begin{array}{l}\text { Donnan model and surface } \\
\text { model (both descriptions } \\
\text { are compared) }\end{array}$ & {$[21]$} \\
\hline $\begin{array}{l}\text { Biosorption of protons onto } \\
\text { chelating resin and } \\
\text { bacterial biomass }\end{array}$ & Donnan model & {$[24]$} \\
\hline
\end{tabular}

The net charge of the biosorbent is in general a function of $\mathrm{pH}_{0}$ and ionic strength, so:

$$
\text { Net charge } \mathrm{Q}=\mathrm{f}\left(\mathrm{pH}_{0}, \mathrm{I}\right)=\mathrm{g}(\mathrm{pH})
$$

where the local $\mathrm{pH}$ at the surface of the biosorbent is:

$$
p H=p H_{0(b u l k)}+\frac{e \psi(I, \text { model })}{2.303 k T}
$$


As a result of the electrostatic effects, the experimental binding curve depends on the ionic strength. A set of measured charge- $\mathrm{pH}_{0}$ curves obtained over a (preferably wide) range of ionic strength is used to optimise the parameters of the electrostatic model (Donnan volume, specific surface area, etc.). If the model for the potential $\Psi$ is correct, the dependence of this binding isotherms on ionic strength should vanish and the charge curves at different ionic strengths plotted versus $\mathrm{pH}$, calculated from Equation 9, yield a single so-called master curve [31] (see Fig. 3). This master curve is independent of the salt level, and can be used for the analysis of the intrinsic binding parameters, for example, by means of an arbitary isotherm.

Obtaining a potential created by a charged particle in an electrolytic solution, which is necessary for being included in Equation 9, entails the resolution of the Poisson or more specifically, the Poisson-Boltzmann equation. According to Bartschat, Cabaniss and Morel [15], this equation can be written as:

$$
\nabla^{2} \Psi=-\frac{1000 F}{\varepsilon}\left(\sum_{i} z_{i}\left[X_{i}\right] \exp \left(-\frac{z_{i} e \Psi}{k T}\right)+\rho_{0}\right)
$$

where $\rho_{0}$ is the charge corresponding to the space region occupied by the biosorbent in $\mathrm{mol} \cdot \mathrm{L}^{-1}$ in the absence of mobile ions and the summation term is the charge density produced by the distribution of co- and counterions in the potential field. This equation accommodates either one phase models (impermeable particles, $\rho_{0}=0$ ) or two phase models, $\rho_{0} \neq 0$.

Apart from the fundamental differences in the approaches of the two models, the macroscopic Donnan model and the microscopic Poisson-Boltzmann theory represent essentially the same electrostatic and osmotic phenomena. In fact, Dähnert and Huster [32] clearly states that an exact solution for the transition of the PB model to the Donnan model has never been presented so they try the question of the intrinsic connection between the two models and show analytically that the Donnan model turns out to be a special case of a more general PB theory. Intuitively this result is not surprising because PoissonBoltzmann equation is one of the expressions of Maxwell's laws: the Poisson equation.

It must be finally underlined that unlike the simple analytical approximation of Debye-Hückel in 1923, the more general non-linear Poisson-Boltzmann equation can be solved today by application of the finite difference method considering the arbitrary shape and charge distribution of molecules offering insight into an important range of biological and chemical phenomena [33]. 


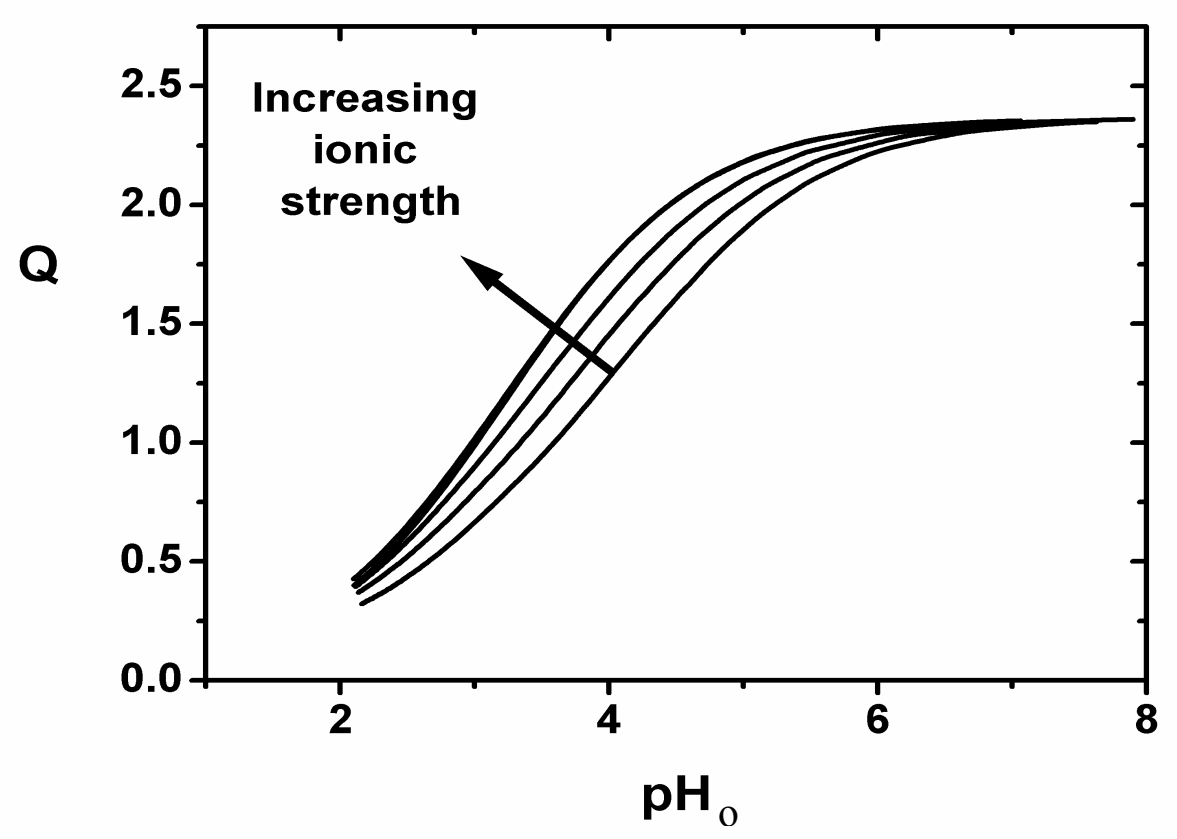

a)

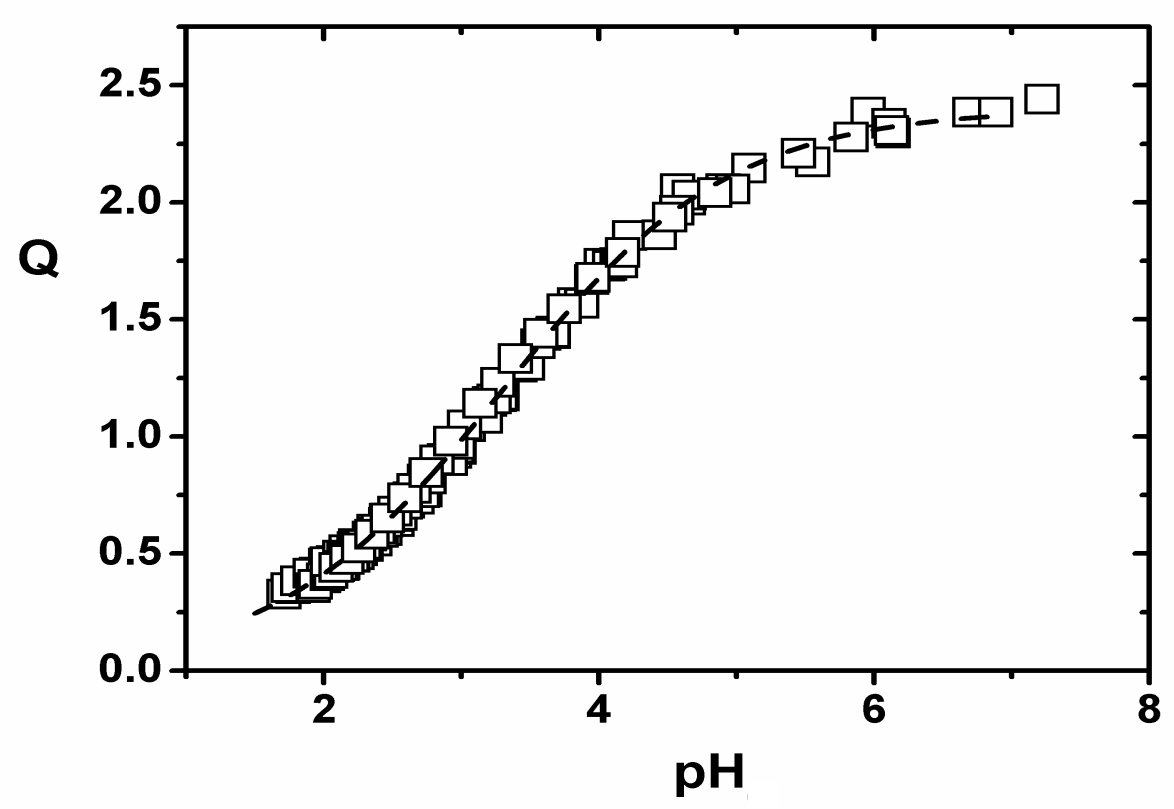

b)

Figure 3. Schematic representation of the procedure for the analysis of proton tritation data (adapted from de Wit el al. [47] using experimental data from Rey-Castro et al. [22].(a) Charge vs. $\mathrm{pH}$ curves of Saccorhiza polyschides in $\mathrm{KNO}_{3}$ at different ionic strengths: $0.05,0.1,0.2,0.7$ and $2 \mathrm{~mol} \cdot \mathrm{L}^{-1}$. (b) Calculated master curve for Saccorhiza polyschides in $\mathrm{KNO}_{3}$. The line represents Langmuir-Freundlich model best fit. 


\section{Acknowledgments}

Authors wish to thank the financial support given by Xunta de Galicia through the project PGIDT02TAM10302PR, Ministerio de Ciencia y Tecnología through the project BQU2002-02133 and Vicerrectorado de Investigación of University of A Coruña.

\section{References}

1. P. Lodeiro, R. Herrero and M.E. Sastre de Vicente, Environ. Chem. 3 (2006) 400-418.

2. B. Volesky, Sorption and Biosorption, BV Sorbex, St. Lambert, Quebec, 2003.

3. J.O.M. Bockris, A.K.N. Reddy and M. Gamboa-Aldeco, Modern Electrochemistry, Vol. 1. Ionics, Plenum Press, New York, 1998.

4. M.E. Sastre de Vicente, Curr. Topics Sol. Chem. 2 (1997) 157-181.

5. $\quad$ M.E. Sastre de Vicente, J. Chem. Educ. 81 (2004) 750-753.

6. K.S. Pitzer, Activity coefficients in electrolyte solutions, CRC Press, Boca Raton, 1991.

7. P.G. Daniele, C. De Stefano, C. Foti and S. Sammartano, Curr. Topics Sol. Chem. 2 (1997) 253-274.

8. F.J. Millero and D. Pierrot, in Chemistry of marine water and sediments, A. Gianguzza, E. Pelizzetti and S. Sammartano, eds., Springer, Berlin; New York, 2002, Chap. 8.

9. C. De Stefano, C. Foti, A. Gianguzza, D. Piazzese and S. Sammartano, in Chemistry of marine water and sediments, A. Gianguzza, E. Pelizzetti and S. Sammartano, eds., Springer, Berlin; New York, 2002, Chap. 9.

10. I. Grenthe, in Chemistry of marine water and sediments, A. Gianguzza, E. Pelizzetti and S. Sammartano, eds., Springer, Berlin; New York, 2002, Chap. 10.

11. M.E. Sastre de Vicente and T. Vilariño, in Chemistry of marine water and sediments, A. Gianguzza, E. Pelizzetti and S. Sammartano, eds., Springer, Berlin; New York, 2002, Chap. 11.

12. D.R. Turner, in IUPAC series on analytical and physical chemistry of environmental systems, A. Tessier and D.R. Turner, eds., Vol. 3. Metal speciation and bioavailability in aquatic systems, J. Wiley, Chichester; New York, 1995.

13. E. Tipping, Cation binding by humic substances, Cambridge University Press, New York, 2002.

14. M. Borkovec, B. Jönsson and G.J.M. Koper, Surface and Colloid Science 16 (2001) 99-399.

15. B.M. Bartschat, S.E. Cabaniss and F.M.M. Morel, Environ. Sci. Technol. 26 (1992) 284-294.

16. J.C.M. de Wit, W.H. Van Riemsdijk and L.K. Koopal, Environ. Sci. Technol. 27 (1993) 2005-2014.

17. T. Saito, S. Nagasaki, S. Tanaka and L.K. Koopal, Colloid Surface A 265 (2005) 104-113. 
18. Z. Reddad, C. Gerente, Y. Andres and P. Le Cloirec, Environ. Sci. Technol. 36 (2002) 2242-2248.

19. D.M. Borrok and J.B. Fein, J. Colloid Interf. Sci. 286 (2005) 110-126.

20. N. Yee and J. Fein, Geochim. Cosmochim. Acta 65 (2001) 2037-2042.

21. C. Rey-Castro, R. Herrero and M.E. Sastre de Vicente, Chem. Spec. Bioavail. 16 (2004) 61-69.

22. C. Rey-Castro, P. Lodeiro, R. Herrero and M.E. Sastre de Vicente, Environ. Sci. Technol. 37 (2003) 5159-5167.

23. C. Rey-Castro, R. Herrero and M.E. Sastre de Vicente, J. Electroanal. Chem. 564 (2004) 223-230.

24. F. Pagnanelli, F. Vegliò and L. Toro, Chemosphere 54 (2004) 905-915.

25. S. Schiewer, J. Appl. Phycol. 11 (1999) 79-87.

26. S. Schiewer and M.H. Wong, Chemosphere 41 (2000) 271-282.

27. S. Schiewer and B. Volesky, Environ. Sci. Technol. 31 (1997) 1863-1871.

28. S. Schiewer and B. Volesky, Environ. Sci. Technol. 31 (1997) 2478-2485.

29. C. De Stefano, A. Gianguzza, D. Piazzese and S. Sammartano, Anal. Bioanal. Chem. 383 (2005) 587-596.

30. M. Sastre and J.A. Santaballa, J. Chem. Educ. 66 (1989) 403-4.

31. L.K. Koopal, T. Saito, J.P. Pinheiro and W.H. van Riemsdijk, Colloid Surface A, 265 (2005) 40-54.

32. K. Dahnert and D. Huster, J. Colloid Interf. Sci. 215 (1999) 131-139.

33. B. Honig and A. Nicholls, Science (Washington, D. C.) 268 (1995) 11449.

34. J.N. Brönsted, J. Am. Chem. Soc. 44 (1922) 938-948.

35. J.N. Brönsted, J. Am. Chem. Soc. 44 (1922) 877-898.

36. P. Debye and E. Hückel, Phys. Z. 24 (1923) 185-206.

37. P. Debye and E. Hückel, Phys. Z. 24 (1923) 305-25.

38. E. Hückel, Phys. Z. 26 (1925) 93-147.

39. E.A. Guggenheim, Philos. Mag. 19 (1935) 588-643.

40. K.S. Pitzer and G. Mayorga, J. Phys. Chem. 77 (1973) 2300-8.

41. K.S. Pitzer, J. Phys. Chem. 77 (1973) 268-77.

42. L. Blum, Mol. Phys. 30 (1975) 1529-35.

43. H.B. Xue, W. Stumm and L. Sigg, Water Res. 22 (1988) 917-926.

44. C. Jeon and W.H. Höll, Hydrometallurgy 71 (2004) 421-428.

45. Y. Jodra and F. Mijangos, Environ. Sci. Technol. 37 (2003) 4362-4367.

46. M.J. Avena, L.K. Koopal and W.H. van Riemsdijk, J. Colloid Interf. Sci. 217 (1999) 37-48.

47. J.C.M. de Wit, W.H. Van Riemsdijk, M.M. Nederlof, D.G. Kinniburgh and L.K. Koopal, Anal. Chim. Acta 232 (1990) 189-207. 